\title{
TECENDO REDES, CONSTRUINDO PONTES: ATENDIMENTO A UMA FAMÍLIA MIGRANTE NA CLÍNICA DE FAMÍLIAS DO INSTITUTO NOOS
}

\begin{tabular}{c}
\hline TEJER REDES, CONSTRUIR PUENTES: ATENCIÓN A UNA \\
FAMILIA MIGRANTE EN LA CLINICA DEL INSTITUTO NOOS \\
\hline WEAVING NETWORKS, BUILDING BRIDGES: ATTENDING A \\
FAMILY OF MIGRANTS IN THE CLINIC OF NOOS INSTITUTE \\
\hline
\end{tabular}

ADRIANA SCOZ DA C. LIMA ${ }^{1}$

LEONORA F. CORSINI ${ }^{1}$

${ }^{1}$ Instituto Noos, São Paulo/SP, Brasil
RESUMO: Neste artigo compartilhamos os desafios que vivenciamos no atendimento em terapia familiar a uma família de migrantes na Clínica Social do Instituto Noos, em São Paulo. A família, de origem boliviana, era composta de mãe e seus três filhos com idades entre 7 e 11 anos. No início do processo, os quatro moravam em um centro de acolhimento sigiloso, uma vez que a mãe havia sofrido agressões e ameaças violentas do seu ex-marido, pai dos três meninos. Acolher na nossa clínica uma família de migrantes que, naquele momento, morava em abrigo sigiloso, foi uma experiência inédita para nós, que gerou muitas interrogações e demandou muita criatividade e flexibilidade para podermos estar juntos e promover a conversação em um contexto tão especial. Ao longo do processo, pudemos refletir sobre 0 quanto de nossas crenças e a nossa postura, inspiradas no Construcionismo Social e nas práticas colaborativas, nos instrumentalizaram para podermos desenvolver este trabalho numa situação tão nova e desafiadora. Podemos destacar a nossa disposição em nos colocar em posição de não saber, ao mesmo tempo ampliando a escuta e a nossa disponibilidade para acolhê-los em suas dores e dilemas tão singulares e tão estrangeiros para nós.

Palavras-chave: Famílias em migração; Violência intrafamiliar; Interculturalidade; Abordagem colaborativo-dialógica; terapia de família.

RESUMEN: En este artículo compartimos los desafíos que experimentamos al brindar terapia familiar a una familia de migrantes en la Clínica Social del Instituto Noos, en São Paulo. La familia, de origen boliviano, estaba compuesta por una madre y sus tres hijos de entre 7 y 11 años. Al comienzo del proceso, los cuatro vivían en un centro de protección reservado, ya que la madre había sufrido agresiones y amenazas violentas por parte de su ex esposo, padre de los tres niños. Dar la bienvenida a una familia de migrantes a nuestra clínica fue, para nosotros, una experiencia sin precedentes, que generó muchas preguntas y exigió mucha creatividad y flexibilidad para poder estar juntos y promover la conversación en un contexto tan especial. A lo largo del proceso, pudimos reflexionar sobre cuánto de nuestras creencias y posturas, inspiradas por el construccionismo social y las prácticas colaborativas, fueron eficaces al proporcionarnos las herramientas para desarrollar este trabajo en una situación tan nueva y desafiante. Resaltamos nuestra voluntad de ponernos en una posición de no saber, y al mismo tiempo de expandir la escucha y afirmar nuestra voluntad de acogerlos en sus dolores y dilemas tan únicos y tan extranjeros para nosotros.

Palabras-claves: Familias en migración; Violencia intrafamiliar; Interculturalidad; Perspectiva colaborativodialógica; terapia de familia

ABSTRACT: In this article, we share the challenges of the experience in attending a family of migrants at the Social Clinic of Instituto Noos, in São Paulo. The family, of Bolivian origin, consisted of a mother and her three children aged between 7 and 11 years. At the beginning of the process, the four lived in a secretive shelter, since the mother suffered aggression and violent threats from her ex-husband, father of the kids. To host in our clinic a family of migrants who, at that time, lived in a secret shelter, was an unprecedented experience for us, which generated many questions and required a lot of creativity and flexibility to be able to be together and promote a conversation in such a special context. Throughout the process, we were able to reflect on how much of our beliefs and our posture, inspired by Social Constructionism and collaborative practices, provided us with the tools to develop this work in such a new and challenging situation. We can highlight our willingness to put ourselves in the position of not knowing, at the same time expanding listening and our disposition to acknowledge their pains and dilemmas, so unique and so strange to us.

Recebido em: 15/12/2019

Aprovado em: 01/03/2020
Keywords: Migrating families; Intrafamily violence; Interculturality; Collaborative-dialogic approach; family therapy. 
Não importa onde você parou, em que momento da vida você cansou, o que importa é que sempre é possível e necessário "Recomeçar".

Recomeçar é dar uma nova chance a si mesmo.

É renovar as esperanças na vida e o mais importante: acreditar em você de novo.

Paulo Roberto Gaefke, Recomeçar

\section{INTRODUÇÃO}

A história deste artigo nasce do desejo de compartilharmos nossa experiência no atendimento a uma família de migrantes na Clínica Social do Instituto Noos ao longo de oito meses no ano de $2018^{1}$. Não pretendemos fazer uma descrição extensiva de todas as sessões do atendimento, mas gostaríamos de destacar alguns momentos que consideramos mais importantes no processo: a primeira sessão acompanhada por equipe reflexiva; a sessão em que convidamos a mãe para ficar no lugar de observação, formando, junto com a dupla de terapeutas, uma equipe reflexiva; e a sessão em que trabalhamos o genograma da família. Entremeando os relatos das sessões, trazemos algumas contribuições teóricas e ideias de autores que têm sido referência importante em nossa prática em terapia familiar, como Tom Andersen, Harlene Anderson e Harold Goolishian e, mais recentemente, Jaakko Seikkula e Peter Rober². Por se tratar de uma situação muito nova em nossa clínica e que nos convidou a ocupar esse lugar estrangeiro, tivemos a oportunidade de exercitar nossa criatividade revisitando recursos que há alguns anos fazem parte da nossa caixa de ferramentas de terapeutas familiares, tais como equipes reflexivas com diferentes formatos e composições (Andersen, 2002; Andersen, 2005; Lax, 1991); o uso do genograma (Carter \& McGoldrick, 1995) como ferramenta geradora de novas narrativas; o uso de jogos e dinâmicas como Escultura (Barberá \& Knappe, 1997); em articulação com a orientação pós-moderna na terapia familiar como prática colaborativo-dialógica (Anderson, 2019; Anderson, 2011; Rober, 2009). Pudemos, além disso, abrir espaço para a experimentação do Questionário das Preocupações, instrumento dialógico formulado por Rober (2017) para iniciar a conversação em terapia de família.

\section{A HISTÓRIA DO ATENDIMENTO}

O primeiro contato das pessoas interessadas em passar pelo processo da terapia familiar no Instituto Noos acontece em sessões de atendimento multifamiliar que denominamos Porta de Entrada. Nesses encontros, nos apresentamos, contamos como é o trabalho que desenvolvemos no Instituto e convidamos as famílias a também se apresentarem, falarem de si e de suas preocupações. Desde 2017, inspiradas pelas ideias de Peter Rober, que redefine a terapia de família como um diálogo ${ }^{3}$,
1 Foram treze encontros no total, realizados entre os meses de maio e novembro de 2018. Ressaltamos que todos os cuidados éticos, permissões e de anonimato foram cumpridos para a escrita deste artigo.

2 Agradecemos a Cecília Cruz Villares por ter nos apresentado as ideias e trabalhos recentes de Jaakko Seikkula e Peter Rober, compartilhando generosamente conosco seus conhecimentos em Open Dialogue por meio do grupo de estudos Introdução às Práticas Dialógicas em Saúde Mental que coordenou no Instituto Noos entre março de 2018 e junho de 2019.

3 Segundo Harlene Anderson, diálogo é aqui entendido, primordialmente, como um conceito, uma orientação, ou, como Wittgenstein sugere, uma "postura" (2019, p. 259). 
4 Ainda sem tradução para o português.

5 Os nomes dos membros da família foram trocados para preservar seu anonimato. A mãe autorizou, através do Termo de Consentimento Livre e Esclarecido, tanto a apresentação que fizemos na X Jornada Paulista de Terapia Familiar (julho de 2019) quanto a publicação do relato do atendimento na forma de artigo.

6 ONG que trabalha com desnutrição e obesidade infantil. um espaço dialógico que convida a falar das preocupações de cada integrante, mas também daquilo que une e conecta a todos como família e conecta os terapeutas com seus clientes, passamos a substituir a palavra "problema", que geralmente dá início a este tipo de conversa inicial, por "preocupação". E introduzimos, como parte do protocolo da Porta de Entrada, o Questionário das Preocupações, que traduzimos para o português a partir dos apêndices do livro In Therapy Together: Family therapy as a dialogue (Rober, 2017) .

Lídia $^{5}$, a mãe da família em questão, uma mulher boliviana de 35 anos, tinha sido casada com Oscar por dez anos. Logo após o nascimento dos dois primeiros filhos do casal, Juan e Miguel, com 11 e 10 anos na época, e com a morte de sua mãe, Lídia decide migrar para São Paulo, cidade em que outros membros da família de Oscar já haviam se estabelecido, trazendo consigo, além dos dois filhos, seus dois irmãos menores. Pouco tempo depois houve uma primeira separação do casal, e nossa cliente regressa à Bolívia com os filhos e os irmãos; não tardou muito para o marido a procurar, convencendo-a a voltar para São Paulo. Lídia decide tentar mais uma vez, deixando Juan e Miguel com suas irmãs mais velhas, e retorna ao Brasil com Oscar. Foi nesse momento que nasceu, em São Paulo, Mario, o filho caçula, então com 7 anos. Desde o início, a relação do casal foi marcada por proibições, agressões, ameaças e traições por parte de Oscar. Mas, como nossa cliente nos explicou, na sociedade boliviana é muito complicado para uma mulher casada se separar, mesmo se no casamento existe violência. É como uma espécie de "tradição" cultural patriarcal e machista difícil de romper. Apesar disso, no início de 2018, após ter passado por uma situação de extrema violência, Lídia decide sair da casa onde morava com os filhos. Faz o registro da ocorrência numa Delegacia da Mulher, obtendo, consequentemente, medida protetiva para impedir a reaproximação de Oscar e a determinação judicial de que ele só manteria contato com os filhos em visitas assistidas. Nesse momento, Lídia, Juan, Miguel e Mario vão para um dos centros de acolhida sigilosos para mulheres vítimas de violência que faz parte da rede da Secretaria de Assistência e Desenvolvimento Social de São Paulo.

Lídia veio com os três filhos Juan, Miguel e Mario, à Porta de Entrada, em maio de 2018. Seu pedido inicial era poder resgatar os vínculos com eles e exercer a maternidade com mais serenidade e menos culpa. Ela se sentia culpada por estar, segundo nos relatou, privando os filhos do convívio com o pai e forçandoos a uma vida errante, fora de sua antiga casa, tendo que mudar de escola com frequência (em alguns momentos, ficando sem escola), sem o conforto que tinham antes, sem a proximidade de parentes e principalmente do pai. Sentia que tinha "roubado" a família dos filhos que acreditavam (um deles chegou a verbalizar isto) que não existe família se todos os seus membros não vivem juntos na mesma casa. Ela também queria saber se estava correta na maneira como vinha educando os filhos; preocupava-se em poder se comunicar melhor com eles, encontrando um equilíbrio entre ser responsável pela educação - o lugar de dar limites e ajudá-los em suas tarefas escolares - e um lugar de mãe mais amorosa. Como nos relatou neste primeiro encontro, quando foi buscar Juan e Miguel, seus dois filhos mais velhos que haviam ficado na Bolívia, houve um estranhamento e eles, por algum tempo, a chamaram de "tia".

A família havia sido encaminhada para a Clínica Social no Instituto por uma das profissionais do CREN - Centro de Reabilitação e Educação Alimentar ${ }^{6}$, que atendia Miguel, o filho do meio, que estava com problemas de sobrepeso. Havia também outra questão cultural que se evidenciou quando os três meninos começaram a apresentar dificuldades na escola, especialmente em leitura e escrita, sendo que Mario ainda não havia conseguido se alfabetizar. Lídia nos contou que tinha ouvido 
de uma fonoaudióloga que a dificuldade de seu filho caçula em aprender a ler e escrever devia-se ao fato de ser estrangeiro e não conseguir falar bem o português, apesar de ele, efetivamente, não falar espanhol. Mario era o "brasileiro" da família.

Além das informações colhidas na Porta de Entrada por meio dos Questionários das Preocupações (Rober, 2017), as assistentes sociais do CREAS (Centro de Referência Especializada em Assistência Social) responsáveis pelo abrigamento da família no centro sigiloso nos disseram que nossa cliente corria de fato um risco muito grande porque, após a separação e apesar da medida protetiva, o ex-marido continuava insistindo em voltar e, diante da recusa de Lídia, a fazer ameaças graves, inclusive de morte. No entanto, as circunstâncias e o episódio de violência sofrida que motivou a separação e a medida protetiva não chegaram a ser explicitados no primeiro encontro. Assim, sabíamos muito pouco, ou melhor, não sabíamos o porquê desta família se encontrar morando em um abrigo sigiloso, não podendo fornecer o endereço ou qualquer número de telefone. Só podíamos nos comunicar por intermédio das assistentes sociais do CREAS.

Ao final deste primeiro contato na Porta de Entrada, após Lídia ter confirmado seu desejo de continuar participando do processo e de levar os filhos, oferecemos, para a primeira sessão, um atendimento com Equipe Reflexiva (Andersen, 2002; Lax,1997). Explicamos brevemente o que iria acontecer naquele primeiro encontro e Lídia aceitou, ficando de pensar se compareceria sozinha ou se levaria os três filhos.

\section{NOSSO NÃO SABER E A ENTRADA DA EQUIPE REFLEXIVA}

Organizamos o encontro que incluiria, além das duas terapeutas que acompanhariam a família, uma equipe de terapeutas que se reunia para um grupo de estudos sobre processos reflexivos às sextas-feiras no Instituto. Seria uma sessão inicial com equipe reflexiva (Lax, 1997). Tínhamos muitas expectativas, curiosidades e interrogações variadas: será que Lídia conseguiria levar os filhos? Haveria condições de nos contar mais sobre a violência que sofrera? Como a família tinha ido parar em um abrigo sigiloso? Como seria encontrar a mãe e seus três filhos com tanta gente presente na sala? Como seguiríamos depois?

Achamos útil relembrar algumas considerações de Harlene Anderson (2011) a respeito do não saber do terapeuta: "se realmente não sabemos, então precisamos aprender. Se tentarmos aprender, então tentamos entender o que o cliente está nos contando. Saber e compreender, nesse sentido, estão sempre no caminho". (p. 114, grifo da autora). A postura do não saber é descrita como um dos recursos que proporciona ao terapeuta a possibilidade de estabelecer essa relação de aprendizagem. Assim, ao exercê-la, o terapeuta se reconhece como aprendiz, deixando em suspenso seus conhecimentos prévios (Anderson, 2007), permanecendo completamente voltado a aprender com as descrições e compreensões de seus clientes. Além disso, não saber e querer aprender com o cliente pressupõe humildade por parte do terapeuta sobre o que o outro sabe (Anderson, 2011, p. 114), bem como a capacidade de tolerar a incerteza (Olson, Seikkula \& Ziedonis, 2014).

Lídia acabou comparecendo com seus filhos Juan, Miguel e Mario, que ficaram bem à vontade, interagiram e participaram da conversa com a dupla de terapeutas. Retomamos os Questionários das Preocupações que haviam sido preenchidos na Porta de Entrada e conversamos sobre o que tinham escrito e desenhado neles. As respostas dos meninos nos ajudaram a entender um pouco melhor o que estava acontecendo naquele momento: Juan apontava a mãe como a mais preocupada da família, mas disse também que o pai se preocupava muito com ela;

Nova Perspectiva Sistêmica, v. 29, n. 66, p. 36-48, abril 2020. 
Miguel ampliou um pouco mais, incluindo um tio, irmão da mãe, que estava triste com a morte do avô e igualmente falou da preocupação do pai com todos eles e de seu próprio desejo de o pai e a mãe voltarem a se entender e de que todos pudessem viver novamente juntos, como quando estavam na Bolívia; Mario, o mais novo, se dizia preocupado com o pai porque ele sentia saudades de Lídia. Pudemos sentir, a partir do que contavam e também dos desenhos que fizeram, que, para os dois mais velhos, havia uma memória de um tempo feliz na Bolívia, quando viviam juntos no que chamaram "fazenda". Em seus desenhos havia árvores, flores e, num deles, se via um grande coração com as pessoas da família dentro, com exceção do pai; o coração estava atravessado pelo que parecia um cinto com fivela (um coração apertado pela saudade? Ou um cinto de segurança para proteger a família?). Mario, o filho caçula, não tinha essas lembranças; o lugar onde ele mais gostava de estar era a escola e em seu desenho víamos uma sala de aula e a legenda, escrita com ajuda da terapeuta que os acompanhou no preenchimento dos questionários, explicando que o que mais gostava era a hora do recreio e a aula de computador. Foi para nós surpreendente (um aprendizado!) observar como, apesar dessas lembranças e preocupações com o pai, os três meninos se dirigiam à Lídia de forma amorosa e respeitosa: as frases e desenhos que depois foram oferecidos a ela continham mensagens como o quanto ela era importante para eles, o quanto a queriam e se preocupavam com ela. Lídia parecia emocionada e surpresa com o carinho dos três meninos, mas voltava a falar de suas dificuldades em cuidar dos filhos e dar conta de uma rotina no abrigo em que era responsável por realizar muitas tarefas diferentes, como lavar louça, cozinhar, cuidar da limpeza para o coletivo do abrigo; muitas vezes tinha a sensação de que tinha de "fazer mais do que as outras mulheres abrigadas" (sic). Não lhe sobrava tempo e disposição para depois ir brincar com os filhos e ajudá-los nas tarefas escolares.

Parecia existir um contraste grande entre o que Lídia descrevia como suas maiores preocupações e as preocupações dos filhos, explicitadas nos questionários e nos desenhos, como se fossem duas linhas de conversa. Como naquele primeiro encontro não haveria tempo para explorarmos mais os desenhos com as crianças, pensamos que seria útil usá-los como meio para abrir conversas nas sessões subsequentes. De acordo com a sugestão de Rober (2017), desenhos feitos espontaneamente numa sessão de terapia de família de orientação pós-moderna podem ser um convite ao diálogo; no lugar de desvelarem conteúdos problemáticos ou patológicos prontos a serem interpretados pelo terapeuta especialista, "os desenhos oferecem um espaço seguro para que os membros de uma família possam refletir sobre suas experiências" (Rober, 2017, p. 157, tradução nossa). Ao mesmo tempo, desenhos e mensagens escritas abrem uma oportunidade aos terapeutas de, não buscando interpretações ou explicações sobre conteúdos, responder confirmando que viram o que foi feito ou dito pelos clientes e, assim que possível, abrir espaço para um novo ponto de vista sobre o que estava sendo conversado no momento (Seikkula, 2011, p. 187).

Ao nos encaminharmos para o término da sessão, fizemos o convite para que as pessoas presentes na sala nos apresentassem suas próprias ideias. $\mathrm{Na}$ conversa da equipe surgiram reflexões muito interessantes, como, por exemplo, a ideia de Lídia poder, talvez, compartilhar com os filhos algumas das tarefas domésticas do abrigo como mais uma forma de estar com eles. Em seus comentários, as integrantes da equipe reflexiva repetiam e confirmavam palavras ditas por Lídia como brincar junto, fazer junto, levar os filhos para eventos culturais na cidade, além de ressaltarem a sua coragem e disposição para recomeçar a vida junto dos filhos e elogiarem aquela família "amorosa".

Depois que encerramos a sessão e a família saiu, convidamos a equipe reflexiva a nos contar como tinha sido participar daquele encontro, que ressonâncias tinham 
sido geradas, o que tinham sentido. Uma das terapeutas então compartilhou conosco seu incômodo com o que nomeou como dificuldade de se iniciar uma terapia com uma família em situação de violência e vulnerabilidade sabendo tão pouco. Esse incômodo manifestado pela nossa colega gerou uma conversa entre nós sobre os limites do não saber, como e quando é útil se colocar nesta posição, o que nos ajuda a manter nossa escuta estrangeira e nossa curiosidade em meio às incertezas, hesitações e não ditos. Afinal, naquele encontro, ninguém tinha abordado ou mesmo pronunciado a palavra violência. Saímos da sessão com a família sem essas respostas, mas acreditando que incluir outras vozes (as preocupações da família e as preocupações e incertezas diante da complexidade do atendimento) e ampliar as nossas próprias vozes ou conversas internas, aquilo que nós tínhamos vivenciado, pensado e sentido, mas não comunicado durante o encontro (Rober, 2009), seria muito importante para podermos continuar. Foi importante para nós não perdemos o propósito, mas podermos renunciar ao lugar de especialistas, privilegiando uma relação horizontal na construção conjunta de realidades preferíveis para família a que atendíamos. A chamada postura do não saber como conceito associado à terapia colaborativa (Rapizo, 1998) nos convida a sermos terapeutas dispostas a conhecer com a família suas próprias formas de entender a si mesmas e seus dilemas e, portanto, a nos colocar em um lugar "estrangeiro" com relação ao que já sabemos.

\section{A HISTÓRIA DA FAMÍLIA}

No encontro seguinte, Lídia chegou com os três filhos, Juan, Miguel e Mario e nesta sessão estaríamos, nós duas, autoras desse relato, atendendo no campo. Perguntamos como gostariam de usar o tempo conosco e Lídia disse que gostaria de poder falar sobre o pai dos meninos, Oscar. Na sua percepção, os filhos pareciam ficar pouco à vontade em falar sobre o pai para não magoá-la. Enquanto ia nos contando sua história, Juan e Miguel desenhavam numa mesa próxima e Mario, o caçula, desenhava perto dela, acompanhando atentamente o seu relato, especialmente nos momentos em que lembrava dos tempos difíceis na Bolívia por ocasião da morte de sua mãe, e da relação difícil com seu próprio pai, avô dos meninos. Seu dilema continuava sendo não afastar os três filhos do pai, por um lado; e, por outro, de que Oscar se aproveitasse disso para insistir que ela voltasse para ele. Em algum momento perguntamos se Juan e Miguel gostariam de participar da conversa; Juan respondeu que não queria saber do pai e Miguel continuou concentrado no seu desenho. No final desse encontro, convidamos a todos para conhecerem a oficina de arranjos florais da $\mathrm{ABRE}^{7}$ que havia acontecido naquela manhã no Instituto; todos se encantaram com as flores e o jardim, e cada um escolheu um buquê para levar para o abrigo.

No terceiro encontro dos dez que havíamos combinado com Lídia havia muitas novidades: ela nos contou que precisariam sair do abrigo, uma vez que o prazo que tinham para estar ali estava encerrando. Os dilemas voltaram com mais intensidade: os meninos com grande expectativa de voltarem para a antiga casa e estarem mais próximos do pai, ao mesmo tempo com receio do que esta reaproximação poderia significar. Juan, especialmente, se emocionou muito ao falar de como não gostaria de ficar longe de sua mãe ou de vê-la em situação de risco. O diálogo seguiu em torno da ideia de como poderiam encontrar uma solução juntos, de cada um poder falar do que sentia e do que esperava. Nesta conversa, Lídia falou do seu plano de tentar recomeçar a vida fora de São Paulo, numa cidade do interior onde tinha
7 A ABRE - Associação Brasileira de Familiares, Amigos e Portadores de Esquizofrenia atua desde 2002 para melhorar a qualidade de vida das pessoas com esquizofrenia e de seus familiares, defender seus direitos, eliminar 0 estigma, disseminar informações e promover o diálogo sobre a natureza e tratamento da esquizofrenia. Alinhada com esta Missão, em 2016 a ABRE criou 0 Laboratório de Criação Casa Azul, nome que homenageia o local que abrigou 0 universo criativo da artista mexicana Frida Kahlo. As atividades do Laboratório tiveram início em março de 2016 com cinco oficinas oferecidas em parceria com o Programa de Esquizofrenia do Departamento de Psiquiatria da UNIFESP - PROESQ: Arte, Escrita, Filosofia, Música e Teatro. Desde então são oferecidas oficinas permanentes, dentre as quais a Oficina de Arranjos Florais "Abre em Flor", uma iniciativa da ABRE em parceria com a Bothânica Paulista, através da doação de folhagens e flores provenientes de festas decoradas pela equipe de Suzana Ceridono. Desde 2017, um grupo coordenado por Cecília Villares - voluntária e diretora da ABRE - vem criando buquês e vasos a serem oferecidos em ações de solidariedade e de captação de recursos para a ABRE. Durante 0 ano de 2018 as oficinas foram realizadas no Instituto Noos. 
uma pessoa da família que poderia abrigá-la por um tempo enquanto procurava trabalho e escola para os meninos. Antes do encontro seguinte, que deveria acontecer quinze dias depois, recebemos o aviso de que não poderiam comparecer por conta da mudança.

Entre uma sessão e outra, num intervalo de quase um mês, avaliamos que, apesar de ser importante que as crianças pudessem ser ouvidas e participar dos diálogos e decisões conjuntas, talvez Lídia tivesse coisas para conversar que não ficaria à vontade de dizer diante dos filhos. Sentíamos que ela precisava de tempo e um espaço seguro para ser mais ouvida e para "se" ouvir com relação aos seus pensamentos sobre o futuro e sobre o passado. E aproveitamos esse intervalo para dar voz a algumas de nossas inquietações e conversas internas: "como pode uma mãe largar tudo assim, desse jeito, sem primeiro providenciar escola para os filhos?"; "essa instabilidade, tantas idas e vindas não irão comprometer a adaptação e integração da família?"; "como farão para restaurar sua rede de referência?"; "mas é importante lembrar que a disposição para partir, deixando tudo para trás, e recomeçar do zero em outro lugar, faz parte da condição migrante”. Como resultado dessa conversa, decidimos convidar uma terceira terapeuta, a mesma que já tinha estado com a família na Porta de Entrada e no primeiro atendimento com equipe reflexiva, a compor conosco uma equipe de atendimento. A entrada desta terceira terapeuta trouxe a possibilidade de oferecermos à Lídia um espaço de interlocução sobre os seus dilemas, ao mesmo tempo oportunizando às crianças um espaço mais livre para se expressarem. Quando a família retornou, ficamos sabendo que a mudança para o interior não tinha dado certo e que Lídia regressara a São Paulo. Havia procurado um irmão de Oscar e, com a ajuda dele, conseguido alugar um espaço para montar um pequeno salão de cabeleireiro e morar com os filhos. Os meninos tinham trocado de escola e Oscar voltara a estar com eles quase que diariamente, as visitas assistidas não estavam mais acontecendo e, o mais preocupante, ele voltara a ter contato com Lídia. Ficamos todas muito apreensivas com a situação de risco em que ela voltara a se colocar, e Lídia nos parecia muito aflita e novamente muito culpada, com medo, sem saber o que fazer.

\section{DA INVISIBILIDADE AO PROTAGONISMO - BOLIVIANOS EM SÃO PAULO}

Gianfranco Cecchin (1996) dizia ser impossível não olhar a realidade através de lentes, sendo essas lentes nada mais do que um conjunto de preconceitos que aprendemos com os anos: experiências pessoais, na família, na escola, que acabam constituindo e moldando nossas visões particulares de mundo. Ao mesmo tempo, sempre entramos nas relações com as lentes dos nossos preconceitos, mas para realizarmos um encontro, é importante existir espaço para existirem os preconceitos do outro (Colombo, 2002, p. 212). Renomeando preconceitos como diferenças culturais, podemos dizer que quando nos encontramos com uma família de origem cultural diversa da nossa somos desafiados a desenvolver competências especiais para lidar com essas diferenças. Em outras palavras, os encontros com pessoas que possuem tradições e visões de mundo muito diferentes ou incomuns com relação às nossas (diferenças culturais) podem trazer à tona pensamentos estereotipados e ideias preconcebidas sobre o que é melhor, mais adequado, mais útil ou mais transformador. Mas, por outro lado, a relação terapêutica que se desenvolve na interculturalidade pode também oferecer ao(s) terapeuta(s) a oportunidade de entrar em contato com o que Rober nomeia como "universalidades" - um senso de humanidade compartilhada (shared humanity) - que vai além das diferenças

Nova Perspectiva Sistêmica, v. 29, n. 66, p. 36-48, abril 2020. 
culturais e das nossas competências enquanto terapeutas em lidar com tais diferenças (Rober \& De Haene, 2014). Assim, buscando entrar em sintonia com esse terreno comum e, simultaneamente, incomum, acreditamos ser útil para o nosso relato trazer um pouco da história da migração boliviana em São Paulo.

A migração de bolivianos para o Brasil é histórica e remonta à segunda metade do século XX. Foi a partir dos anos 2000, porém, que a comunidade boliviana no Brasil cresceu exponencialmente. Hoje, estima-se que vivam no país cerca de 250.000 pessoas desta nacionalidade, sendo São Paulo o principal destino desses migrantes. Muitos bolivianos não conseguem regularizar sua situação migratória, obter documentos, abrir conta no banco, ter condições para alugar uma moradia. Assim, acabam sendo, na maior parte das vezes, encaminhados para uma situação de clandestinidade e invisibilidade, trabalhando em ateliês de costura, frequentemente em condições de extrema exploração, e até mesmo análogas à escravidão.

Mesmo nessas condições que os levam a ficarem invisíveis, escondidos nos subterrâneos dos ateliês de costura que povoam as regiões do centro e zona leste da cidade de São Paulo (bairros como Bom Retiro, Brás, Mooca, Pari, na região central, até São Miguel Paulista e Cangaíba, na zona Leste), desde o início dos anos 2000 os bolivianos de São Paulo começaram a se organizar e formar associações de bairro, realizando caminhadas até o consulado da Bolívia para pressionar por mais direitos, acesso ao trabalho regular, moradia, escola para os filhos etc. Em 2006, durante a Marcha dos Migrantes que acontece anualmente na cidade, houve grande participação de bolivianos. Mesmo assim, passaram-se alguns anos até que a situação dos migrantes bolivianos na capital paulista mudasse de perfil e algumas de suas pautas fossem atendidas. Hoje, atividades culturais como as tradicionais festas de Nossa Senhora de Copacabana, as feiras dominicais na Praça Kantuta $^{8}$, a feira que acontece aos sábados na rua Coimbra ${ }^{9}$ no bairro do Brás onde, além de gastronomia, são oferecidos à comunidade serviços de cabeleireiro, acesso à internet (Lan Houses), agências para remessas de divisas e casas de câmbio, já fazem parte do cenário cultural paulistano. Além disso, a comunidade boliviana passou a contar com uma unidade do Consulado da Bolívia no bairro do Brás.

Essa história da presença boliviana em São Paulo lança algumas luzes nas histórias que nossos clientes nos contaram, como, por exemplo, a aparente facilidade com que Lídia encarava morar com todos os filhos em um quarto no local de trabalho onde funcionavam Lan Houses e pequenos salões de cabeleireiro (ela sempre exerceu este ofício); o medo que tinha de se aproximar de locais frequentados por pessoas da comunidade boliviana, algo que em alguns momentos pensamos em sugerir; os silêncios e as hesitações dos meninos com relação ao local de moradia; a repentina decisão de se mudar para outra cidade, deixando o abrigo sigiloso para tentar uma vida nova onde não conhecia ninguém além de um parente e a importância das redes familiares em termos de apoio financeiro, abrigamento, tomada de decisões.

Ao trazermos nossas conversas internas e refletirmos sobre como nos sentíamos impactadas com as idas e vindas de Lídia, percebemos o quanto as nossas "lentes" contrastavam (muitas vezes não deixando espaço) com as crenças dela e dos filhos acerca da importância da presença do pai na vida da família, mesmo quando este não é um pai amoroso ou dedicado e é até ameaçador; a facilidade que ela demonstrava em deixar tudo para trás e partir para recomeçar em outro bairro, outra cidade, outro país, sem pensar ou planejar muito, "sem lenço e sem documento", como diz a canção. No lugar de imprudência, negligência e falta de responsabilidade daquela mãe, talvez essas decisões estivessem sinalizando que ela tentava sair de um ciclo de clandestinidade e fuga, elementos que tantas vezes estão presentes nas trajetórias de migrantes, retomando o protagonismo de sua própria história.
8 A Feira da Praça Kantuta, que acontece todos os domingos no bairro do Pari, é um ponto de encontro de imigrantes, bolivianos em sua maioria, e é onde ocorre uma feira gastronômica, numa tentativa de preservar a identidade cultural destes que vêm ao Brasil em busca de trabalho e melhores condições de vida. Kantuta é o nome de uma flor típica do altiplano andino e suas cores - verde vermelho e amarelo - são as mesmas da bandeira oficial da Bolívia. (Fonte: https:// www.destakjornal.com.br/ sao-paulo-city/detalhe/feirakantuta-um-pedacinho-dabolivia-em-sao-paulo). Para mais informações, ver também Garcia, 2016.

9 "A rua Coimbra é para 0 povo boliviano 0 que a avenida Paulista é para o paulistano. É o lugar onde nosso povo mora, trabalha, comercializa os nossos produtos e faz nossa cultura. Essa é uma conquista do povo boliviano após muitos anos de luta e achamos que será um novo tempo para os bolivianos de São Paulo", afirma o presidente da Assempbol, Luis Vasquez Mamani, que faz parte do Conselho Participativo Municipal, criado em 2013. (Fonte: http://www. capital.sp.gov.br/noticia/feirade-bolivianos-da-rua-coimbrae-regularizada). 


\section{AMPLIANDO A REDE E OS RECURSOS TERAPÊUTICOS}

Introduzimos aqui a ideia de rede no sentido proposto por Carlos Sluzki (1998), que utiliza a rede social como metáfora para o trabalho com famílias desde a perspectiva sistêmica. Sluzki procura, em seu trabalho sobre o uso do mapa da rede social na terapia familiar, uma conexão entre o pensamento sistêmico e o construcionismo social, aliando-a à sua experiência em psiquiatria comunitária o compromisso político e a sua própria experiência de vida como migrante argentino radicado nos Estados Unidos. Com efeito, neste que é o seu trabalho mais difundido entre terapeutas familiares, Sluzki redefine o processo migratório como um experimento natural de fratura e reconstrução da rede social de um indivíduo ou de uma família. No caso da família que atendíamos, tanto a experiência de rompimento de laços quanto a necessidade de uma nova rede de vínculos e pertencimento se tornavam evidentes para nós, mas esbarravam no medo, sobretudo por parte de Lídia, de encontrar-se com pessoas da comunidade boliviana, mesmo pessoas sem relação com sua família.

Consideramos nesse momento que seria importante Lídia ter um espaço terapêutico só para ela e entramos em contato com o Projeto Ponte Sedes ${ }^{\mathbf{1 0}}$, programa do Instituto Sedes Sapientiae para atendimento a pessoas e famílias migrantes. O objetivo desse grupo de trabalho é oferecer atendimento psicológico/psicanalítico a refugiados, migrantes internos e internacionais, exilados, indocumentados, brasileiros retornados, enfim, todos aqueles que apresentam uma demanda por terapia relacionada ao sofrimento advindo da migração. Esses atendimentos, oferecidos a migrantes, em sua maioria proveniente de países latino-americanos e do continente africano, são, preferencialmente, grupais, mas também podem ser familiares, institucionais e individuais. Um dos orientadores clínicos do projeto se baseia na sustentação do lugar de estrangeiro assumido pelo terapeuta/coordenador do grupo, o que fazia muito sentido para nós.

Avaliamos igualmente que seria de muita ajuda se Lídia pudesse contar com uma orientação jurídica, já que tinha muito medo de perder a guarda dos filhos por não os estar levando nas visitas assistidas (afinal, Juan, Miguel e Mario já estavam vendo o pai fora dessas visitas) e por ter decidido morar novamente perto de Oscar,

100 Projeto Ponte Sedes foi criado em 2010 e funciona na clínica psicológica do Instituto Sedes Sapientiae. 0 Sedes Sapientiae é um marco na cidade de São Paulo devido à sua posição política na defesa dos direitos humanos. $\mathrm{Na}$ época da ditadura no Brasil e em países vizinhos, o Sedes acolheu em sua casa vários migrantes e exilados políticos, que mais tarde contribuíram na construção do próprio Departamento de Psicanálise da instituição (Yu et al., 2018). Agradecemos a Carol Yu e Liliana Emparan, integrantes do projeto, pela sua disponibilidade em construir esta "ponte", uma parceria que se revelou muito valiosa na construção desse trabalho. permitindo que ele voltasse a se aproximar. Lídia concordou com nossas sugestões, entrou em contato com o Sedes para se inscrever para a terapia, que começou logo em seguida, e concordou também em telefonar para o NUDEM - Núcleo de Promoção e Defesa dos Direitos da Mulher, da Defensoria Pública de São Paulo. Foi novamente orientada a sair de perto do ex-marido e procurar um lugar para morar com os filhos em que não tivesse que viver com medo e tendo que fugir o tempo todo. E também para retomar as visitas assistidas, nas datas e horários estabelecidos.

As crianças, especialmente o filho menor, Mario, apresentavam problemas de aprendizagem. Mario, aos 7 anos, com uma fala sem encadeamento das ideias, trocava e omitia letras, prejudicando a compreensão de quem o escutava, fazendo pensar em um processo de alfabetização ainda defasado. Tanto as três terapeutas como a mãe e os irmãos tínhamos dificuldade em compreendê-lo, o que o deixava irritado por não conseguir se fazer entender. Nesse momento ficamos sabendo que Lídia havia procurado atendimento na Trapézio - associação sem fins lucrativos que, desde 1995, atua nos impasses escolares, permitindo que crianças e jovens, cuja escolarização esteve em risco, recuperem a vivacidade, curiosidade e empenho em suas aprendizagens -, que desenvolve ações de apoio à escolarização beneficiando alunos, pais e educadores. Não tivemos oportunidade de conversar com a psicopedagoga que 
iniciou o atendimento de Mario, tratamento que, depois soubemos, foi descontinuado por conta das mudanças de moradia, escola e até de cidade.

A entrada da terceira terapeuta e o convite feito a duas outras colegas para participarem como equipe reflexiva visitante ${ }^{11}$ foram muito importantes no processo, pois permitiram focar mais as questões de aprendizagem e integração cultural das crianças, enquanto nós duas, autoras do artigo, fazíamos recortes de tempos e espaços, propondo momentos em que todos conversávamos juntos; momentos para jogos, dinâmicas e conversas dos três meninos com a terceira terapeuta; e momentos em que nós duas ficávamos só com Lídia. A esta altura, ela havia se mudado novamente, já estava em um novo abrigo com os filhos, num bairro bem afastado do lugar onde morava antes. Sua expectativa era de poder recomeçar a vida, encontrar trabalho e matricular os filhos novamente na escola.

E começávamos a ouvir dos meninos, talvez como resposta àquelas mudanças introduzidas na terapia (a entrada de uma nova terapeuta, a equipe reflexiva "visitante", composta pela outra dupla de terapeutas), que gostariam de dividir melhor os tempos de brincadeira e tempos de conversa nas sessões. Por eles, conversaríamos um pouquinho, e depois teríamos só brincadeiras e jogos. Percebíamos que Lídia, que naquele momento já estava indo no grupo terapêutico do Sedes e já tinha se acalmado com as orientações recebidas da Defensoria, ficava mais calada. Sugerimos então uma nova mudança: estaríamos todos na mesma sala de jogos e, enquanto os meninos brincavam com a terceira terapeuta, Lídia ficaria observando e escutando junto com a dupla, compondo uma equipe reflexiva. No momento que a convidamos para compartilhar conosco suas ideias ela contou que tinha sido para ela uma experiência muito diferente poder observar os filhos interagindo e brincando; em geral, ela se sentia "obrigada" a sentar e brincar com eles. Era uma sensação nova, estar junto, sentir-se próxima, mas poder fazer outra atividade, ou apenas observálos. Parecia, nas suas palavras, muito libertador. Ao mesmo tempo, compartilhamos nossa reflexão de que as combinações e divisões de tempos e espaços que aconteciam na terapia poderiam acontecer também no lugar onde estivessem morando, e que era importante poder conversar e planejar juntos essas divisões.

\section{MESMO VIVENDO EM DIFERENTES PAÍSES, SOMOS UMA FAMÍLIA}

Como mencionamos, um dos dilemas centrais de Lídia era não privar seus filhos de um pai, uma história, uma família. Ao mesmo tempo, tinha receio de que evocar essa história pudesse trazer de volta fantasmas e medos, atuais e antigos, e fazer os meninos reviverem situações traumáticas.

Numa sessão que aconteceu em novembro de 2018, dissemos que conhecíamos um jeito de contar a história da família através de um mapa com desenhos e símbolos, que poderíamos construir junto com eles, o genograma (Carter \& McGoldrick, 1995). Eles gostaram da ideia e, na sessão seguinte, preparamos a sala colocando o flip-chart no centro, as cadeiras em semicírculo e perguntamos quem gostaria de iniciar o relato. Todos concordaram que Lídia deveria começar a contar a história. Explicamos que desenharíamos círculos representando as mulheres e quadrados representando os homens personagens daquela história, e que os três, Juan, Miguel e Mario, poderiam completar com informações e desenhos.

À medida que Lídia ia nomeando as pessoas de sua família, perguntávamos em que país cada um vivia naquele momento. Daí surgiu a ideia de os meninos escreverem as iniciais de cada país com as suas respectivas cores: verde e amarelo para Brasil (BR): vermelho, verde e amarelo para Bolívia (BOL); azul e branco para Argentina (AR).
11 Nosso agradecimento a Patrícia Ottaiano, Ana Luisa Coutinho e Maitá Figueiredo, que aceitaram 0 desafio de construir conosco essas inovações na nossa prática, e cuja participação e interlocução foram fundamentais para 0 atendimento. 
Lídia conseguiu também nomear os familiares de Oscar, relembrou os nomes dos pais dele, seus sogros, e da maioria dos irmãos, muitos dos quais estabelecidos no Brasil. Os meninos ouviam maravilhados os nomes e as histórias e, em alguns momentos, pediam para complementar alguma informação ou para fazer um desenho. Foi um momento de muita emoção, em que encontráramos uma forma de Oscar também participar. Foi igualmente uma oportunidade para que os três meninos negociassem entre si quem iria acrescentar um desenho, colocar alguma letra ou marca no genograma. Já no final, demos muitas risadas quando Mario se lembrou: "falta colocar o pai de todos, que é Jesus! E tem que ser quadrado, porque Jesus é menino!". Como ele ainda não conseguia escrever e também não alcançava o topo do flip-chart, escrevemos J E S U S em um pedaço de papel para ele copiar e o irmão mais velho o segurou pelas pernas para que pudesse colocar o quadrado no alto da folha.

Em um momento em que estava só conosco, Lídia havia falado de sua tristeza quando ouviu Miguel, o filho do meio, dizer que, para voltarem a ser uma família, tinham que estar todos juntos na mesma casa. Conversamos mais um pouco sobre experiências de pessoas que migram para outro país e que, mesmo estando distantes geograficamente, continuam tendo uma família nos lugares de onde vieram; essa era também a sua história - seus pais e alguns irmãos, tios, sobrinhos, ainda estavam lá na Bolívia. E pudemos depois refletir que a construção coletiva da história daquela família de migrantes através do genograma parecia ter devolvido um sentido de pertencimento, e talvez tivesse sido uma forma de Lídia dar um novo sentido à sua separação de Oscar.

\section{DANDO VOZ ÀS NOSSAS CONVERSAS INTERNAS, À GUISA DE CONCLUSÃO}

Participar do atendimento a essa família foi um instigante desafio para nós, especialmente por se tratar de uma família de imigrantes em situação de vulnerabilidade. Ao longo do processo, que se encerrou em novembro de 2018, pudemos refletir sobre o quanto de nossas crenças e a nossa postura, inspiradas na abordagem dialógica e nas práticas colaborativas, nos instrumentalizaram para podermos desenvolver este trabalho numa situação tão nova e desafiadora. Podemos destacar que a nossa disposição em adotarmos a postura de não saber e nos tornarmos "estrangeiras" diante da família facilitou que ela pudesse ser protagonista da sua própria história. Pudemos, ao mesmo tempo, manter nossa disposição em acolhê-los em suas dores e dilemas tão singulares.

Construindo nosso caminho enquanto caminhávamos, fomos ampliando nossos olhares em busca de saídas para as demandas e novos sentidos para as preocupações que a família nos apresentava a cada encontro e fomos também aprendendo com ela. Ao mesmo tempo, pudemos mobilizar antigos e novos recursos que operaram como facilitadores do processo de entrar em contato com uma situação tão incomum e, ao mesmo tempo, tão "demasiadamente humana".

Hoje, revisitando todo o processo, tornamos a dar voz a algumas de nossas falas internas que não chegaram a ser enunciadas, mas que estavam lá presentes o tempo todo: um vivo interesse, já de alguns anos, por parte de uma das terapeutas, pela questão migratória e todas as suas implicações subjetivas, culturais, de direitos humanos e cidadania; a conexão/identificação com a situação de mulher que passou por situação de violência familiar e precisou recorrer a órgãos e serviços de proteção; e a preocupação das outras terapeutas da equipe, com os efeitos das interrupções do ano letivo e mudanças de escola, além do fato de crianças em idade escolar estarem fora da escola, o que contraria a legislação brasileira e o Estatuto da Criança e do 
Adolescente (ECA). Essa última preocupação com a escolaridade das crianças chegou ser externalizada em um momento em que conversávamos só com Lídia.

Em fevereiro de 2019 fizemos contato telefônico com Lídia para saber como estavam. Ela nos contou que Miguel continuava fazendo o trabalho de reeducação alimentar no CREN. Estava ainda aguardando a formalização da matrícula dos meninos na nova escola, processo que havia sofrido atraso porque o centro de acolhimento só então havia retirado o sigilo do endereço residencial. Os meninos estavam se encontrando com Oscar livremente, não mais em visitas assistidas. E ela continuava em seu caminho, trabalhando como cabeleireira, morando no local de trabalho, sonhando em um dia poder voltar a ter uma casa para morar com seus filhos Juan, Miguel e Mario.

\section{REFERÊNCIAS}

Andersen, T. (2005) Procesos de reflexión - actos informativos y formativos. In: Steven Friedman (2005) Terapia Familiar con Equipo de Reflexión. Una práctica de colaboración. Trad. ZoráideValcárel. Madri: Amarrortu Editores.

Andersen, T. Processos Reflexivos (2002). Rio de Janeiro: Instituto Noos, $2^{\text {a }}$ edição ampliada.

Anderson, H. (2019) Prática colaborativo-dialógica: uma orientação para maneiras de ser e vir a ser com outros convidando o potencial para generatividade e transformação. In: Marilene Grandesso (org.) Construcionismo Social e práticas colaborativo-dialógicas: contextos de ações transformadoras. Curitiba: Editora CRV.

Anderson, H. (2011) Conversação, linguagem e possibilidades. Um enfoque pós-moderno da terapia. Edição revisada, São Paulo: Roca.

Anderson, H. (2007) Dialogue: People creating meaning with each other and finding ways to go on. Nova York: Routledge.

Anderson, H.; Goolishian, H. (1998) O cliente é o especialista: a abordagem terapêutica do não-saber. In: McNamee, S.; Gergen, K. (Orgs.). A terapia como construção social. Porto Alegre: Artes Médicas, 1998. p.34-50.

Barberá, E. L.; Knappe, P. P. (1997) La escultura y otras técnicas psicodramáticas aplicadas en psicoterapia. $1^{\text {a }}$ edição, Barcelona: Paidós.

Carter, B.: McGoldrick, M. (1995) As Mudanças no Ciclo de Vida Familiar: uma estrutura para a Terapia Familiar. 2a ed. Porto Alegre: Artmed.

Cecchin, G. (1996) Los prejuicios sistémicos. Entrevista a Claudio Des Champs e Fernando Torrente. Buenos Aires, Perspectivas Sistémicas, n. 43.

Colombo, S. (2002) Abrindo conversações. In: Helena Maffei Cruz (org.) Papai, mamãe, você... e eu? $2^{\text {a }}$ edição, São Paulo: Casa do Psicólogo.

Garcia, L. de F. (2016) (org.) Histórias que se cruzam na Kantuta. São Paulo: VGL Publishing.

Lax W. (1991) The reflecting team and the initial consultation. In: Tom Andersen (ed.) The Reflecting Team - Dialogues and Dialogues about the Dialogues. Nova York: W. W. Norton.

Olson, M.: Seikkula, J.; Ziedonis, D. (2014) The key elements of dialogic practice in Open Dialogue: Fidelity criteria. The University of Massachusetts Medical School. Worcester, Ma.

Rapizo, R. (1998) Terapia Sistêmica de Família. Da instrução à construção. Rio de Janeiro: Instituto Noos.

Rober, P: (2017) In Therapy together. Family therapy as a dialogue. Londres: Palgrave, Macmillan Publishers Ltd. 
Rober, Pn (2009) A conversa interna do terapeuta na prática da terapia de família: lidando com as complexidades dos encontros terapêuticos com famílias. Nova Perspectiva Sistêmica n. 35, p. 46-60.

Rober, $\mathbf{P}_{n}$; De Haene, L.(2014) Intercultural therapy and the limitations of a cultural competency framework: about cultural diferences, universalities and the unresolved tension between them. Journal of Family Therapy, vol. 36, n. 1.

Sayad, A. (1999) La double absence: des illusions de l'émigré aux souffrances de l'immigré. Paris: Éditions de Seuil.

Seikkula, J. (2011) Becoming Dialogical: Psychoterapy or a way of life? The Australian and New Zealand Journal of Family Therapy. Vol 32, n. 3, p. 179-193.

Sluzki, C. (1998) La red social: frontera de la practica sistémica. Barcelona: Editorial Gedisa.

Yu, C. S. Y.; Sagula, C. A. B.; Silva, H. S. de A.; Emparan, L.; Weissmann, L. \& Prata, V. (2018) Um olhar para a cultura, singularidade e saúde mental: o trabalho do Projeto Ponte Sedes. Travessia - Revista do Migrante. Dossiê Migrações e Saúde, n. 84, p. 69-76. São Paulo: Centro de Estudos Migratórios.

\section{ADRIANA SCOZ DA C. LIMA}

Pedadoga, com certificação Internacional em Práticas Colaborativas e Dialógicas - ICCP 2019. Associada efetiva, membro do Conselho Gestor e Coordenadora do Núcleo de mediação do Instituto Noos. Atua como terapeuta de casal e família e mediadora no Instituto e no consultório.

https://orcid.org/0000-0002-8917-1994

E-mail: adrianasclima15@gmail.com

\section{LEONORA F. CORSINI}

Psicóloga, mestre em Psicologia Social e doutora em Serviço Social pela UFRJ. Pesquisadora associada ao LABTeC Laboratório Território e Comunicação da UFRJ, com dedicação aos estudos migratórios. Terapeuta de Família e Psicoterapeuta, associada efetiva do Instituto Noos, membro do Conselho Gestor e Coordenadora da Clínica Social.

https://orcid.org/0000-0002-7192-0432

E-mail: corsinileonora@gmail.com 